\section{Side effects of external tooth bleaching: a multi-centre practice- based prospective study}

\author{
E. M. Bruzell, ${ }^{* 1}$ U. Pallesen, ${ }^{2}$ N. Rygh Thoresen, ${ }^{3}$ C. Wallman ${ }^{4}$ and J. E. Dahl ${ }^{5}$
}

VERIFIABLE CPD PAPER

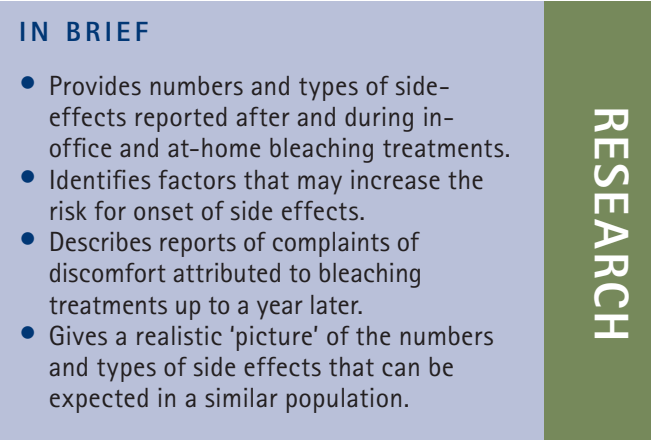

\begin{abstract}
Objective The study was performed to assess the risk of at-home and in-office bleaching procedures, and to recognise potential predictors for side effects. Design Multi-centre, questionnaire-based prospective study with follow-ups at around 14 days and around one year post-treatment. Setting General practices and university clinics during the years 2007-2009 in Scandinavia. Subjects Patients with tooth bleaching as part of the treatment plan. Results The prevalence of experienced tooth sensitivity at first follow-up was independent of bleaching procedure (at-home $=50.3 \%$ [ $n=143]$; in-office $=39.3 \%[n=28] ; p>0.05 ; 95 \% \mathrm{Cl}[\mathrm{OR}]: 0.198-1.102)$ whereas prevalence of gingival irritation was higher after in-office treatment (at-home $=14.0 \%$; in-office $=35.7 \% ; p<0.05)$ (mean age: 37.3 years; $73.7 \%$ women; $n=171)$. At the second follow-up, two and three patients reported side effects attributed to the bleaching treatment in the at-home and in-office groups, respectively. Predictors for side effects were tooth sensitivity, surface loss and gingivitis when observed at inclusion. Treatment-related predictors were bleaching concentration and contact between tray and gingiva. Conclusions Bleaching treatment, irrespective of method, caused a high prevalence of side effects. Patients associated with the predictors at inclusion mentioned above should be notified of the risk for side effects and treated only if bleaching is indicated based on a proper diagnosis.
\end{abstract}

\section{INTRODUCTION}

Tooth bleaching can be carried out successfully as a more conservative approach to improving aesthetics compared to other options such as air or chemical erosion, composite bonding, and the more tooth destructive use of veneers and crowns. Bleaching can be performed or supervised by dental professionals such as in-office (I-O) bleaching and at-home (A-H)

\footnotetext{
Senior Researcher, Nordic Institute of Dental Materials (NIOM), Sognsveien 70A, NO-0855 Oslo, Norway; ${ }^{2}$ Chief Dental Officer, Department of Cariology and Endodontics, School of Dentistry, University of Copenhagen, Nørre Allé 20, DK-2200 Copenhagen N, Denmark; ${ }^{3}$ Lecturer, Cariology and Gerodontology, Institute of Clinical Dentistry, Faculty of Dentistry, University of Oslo, P.O. Box 1109 Blindern, N0-0317 Oslo, Norway: ${ }^{4}$ Associate Professor, Institute of Clinical Dentistryl Faculty of Medicine, University of Troms $\emptyset$, N0-9037 Troms $\emptyset$, Norway: ${ }^{5}$ Managing Director, Nordic Institute of Dental Materials (NIOM), P.O. Box 3,874 Ullevål stadion, N0-0805 Oslo, Norway and Professor, Institute of Clinical Dentistry, Faculty of Dentistry, University of Oslo, P.O. Box 1109 Blindern, NO-0317 Oslo, Norway

${ }^{*}$ Correspondence to: E. M. Bruzell

Email:ebr@niom.no; Tel: +47 67512200
}

Online article number E17

Refereed Paper - accepted 16 July 2013

DOI: 10.1038/sj.bdj.2013.1047

${ }^{\circledR}$ British Dental Journal 2013; 215: E17 treatment, or be carried out entirely by the patient using over-the-counter products. ${ }^{1-4}$

There is no clear indication or recommendation for the selection of bleaching procedure. I-O bleaching is useful for the removal of discolouration throughout the arch, of a few teeth or even treating specific areas of a single tooth. The provider is in complete control of the process throughout treatment and the results are often evident after a single visit. Many patients prefer I-O bleaching by the dental professional because it requires less active participation on their part. ${ }^{5} \mathrm{~A}-\mathrm{H}$ bleaching treatment is suitable for treating the entire arch; it requires patient compliance and gives the patient control of the treatment. This treatment provides the advantage of continuing or terminating the bleaching process at any time and cost-saving reuse of the bleaching tray. In a comparative study on patient satisfaction, subjects preferred and would recommend $\mathrm{A}-\mathrm{H}$ treatment over I-0 bleaching. ${ }^{6}$

For both procedures the bleaching outcomes are based mostly on the effects of hydrogen peroxide $\left(\mathrm{H}_{2} \mathrm{O}_{2}\right.$; $\left.\mathrm{HP}\right)$ and carbamide peroxide $\left(\mathrm{H}_{2} \mathrm{NCONH}_{2} \cdot \mathrm{H}_{2} \mathrm{O}_{2}\right.$; $\left.\mathrm{CP}\right)$, releasing about 33\% of their content as HP. ${ }^{7} \mathrm{HP}$ can act as a powerful oxidising agent and can give rise to products such as free radicals known to be effective bleaching agents. ${ }^{8}$

The safety of professional tooth bleaching has been addressed in a number of reviews. ${ }^{3,7-10}$ Tooth sensitivities and erosive damage of the oral mucosa are frequently reported in the clinical setting. In addition, the alteration of the enamel surface, reduced polymerisation of resin-based materials, and the release of components of restorative materials have been addressed as important phenomena to consider. ${ }^{3}$ Furthermore, it is unclear whether some patients are more prone to side effects than others and which risk factors are involved. The published studies vary in CP and HP concentrations, treatment durations and regimens. The limited number of patients and short follow-up period often found in the studies make evaluation of risk factors for side effects difficult. Risk assessment has revealed that the safety limit may be 
exceeded in cases of extensive use of A-H bleaching agents with $\mathrm{CP}$ and $\mathrm{HP},{ }^{7}$ which should indicate a risk of side effects.

The aim of the present study was to assess the risk of local side effects occurring after practice-based, professional, external tooth bleaching was performed either via I-O or A-H. Our hypothesis is that I-O bleaching represents less risk, as the bleaching agent is handled and observed by a professional throughout the procedure.

\section{DESIGN, SUBJECTS AND METHODS}

\section{Study design}

This prospective survey consisted of questionnaires answered in part by the patients undergoing tooth bleaching and by the dental personnel who performed the treatment (termed 'provider' throughout the text). The patients were recruited from university clinics and private dental offices in Denmark, Norway and Sweden. Each patient served as his or her own control (preversus post-treatment). Three coordinators (UP, NRT and CW) recruited the participating dental personnel $(n=11)$. Preparation of the questionnaires was a joint effort of the authors. The questionnaires were identical except for the language used (Danish, Norwegian, Swedish). The study period lasted from May 2007 to December 2009.

\section{Personal information processing}

The survey institution (Nordic Institute of Dental Materials, NIOM) obtained a licence from the Norwegian Data Inspectorate for processing personal information according to the national act on personal health data filing system. ${ }^{11}$ Upon inclusion in the survey, each patient questionnaire was coded. This code was later converted into consecutive numbers for data processing. The electronic handling of patient information data was processed locally using an external hard disc.

\section{Treatment criteria}

\section{Inclusion criteria}

Patients above 18 years of age with good oral health and external tooth bleaching as part of the treatment plan, as decided by the provider, were included. The minimum number of teeth to be bleached was four. Patients who had undergone single-tooth internal bleaching were included.

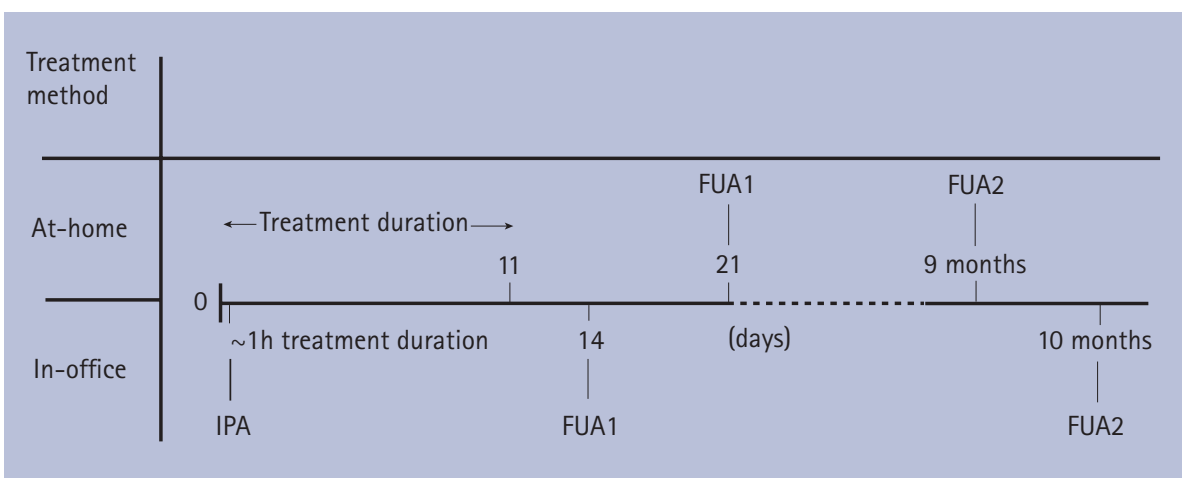

Fig. 1 Bleaching treatment and side effect assessment schedule. FUA1 and FUA2: first and second follow-up assessment, respectively, after end of treatment; IPA: immediate follow-up assessment after in-office bleaching

Table 1 Number-, gender- and age distribution of 171 patients who underwent at-home (A-H) or in-office ( $(\mathrm{O}-0)$ bleaching treatment as well as number- and gender distribution of 152 patients who completed second follow-up (FUA2) (87.4\% and $96.4 \%$ of the total number of patients in $\mathrm{A}-\mathrm{H}$ and $\mathrm{I}-\mathbf{0}$ groups, respectively). Age and gender were equally distributed between bleaching method groups $(p>0.05)$

\begin{tabular}{l|l|l|l|l|l|l|}
\hline & At-home & Women & Total & Men & Women & Total \\
\cline { 2 - 7 } & Men & In-office \\
\hline No. of patients (\%) & $35(24.5)$ & $108(75.5)^{\circ}$ & $143(100.0)$ & $10(35.7)$ & $18(64.3)$ & $28(100.0)$ \\
\hline $\begin{array}{l}\text { Mean age } \pm \text { SD } \\
\text { (range), years }\end{array}$ & $\begin{array}{l}38.3 \pm 14.8 \\
(17-72)\end{array}$ & $\begin{array}{l}36.1 \pm 14.7 \\
(19-84)\end{array}$ & $\begin{array}{l}36.6 \pm 14.7 \\
(17-84)\end{array}$ & $\begin{array}{l}38.6 \pm 11.4 \\
(27-54)\end{array}$ & $\begin{array}{l}42.1 \pm 13.5 \\
(24-67)\end{array}$ & $\begin{array}{l}40.8 \pm 12.7 \\
(24-67)\end{array}$ \\
\hline $\begin{array}{l}\text { No. of patients } \\
(\%) \text { at FUA2 }\end{array}$ & $32(25.6)$ & $93(74.4)$ & $125(100.0)$ & $10(37.0)$ & $17(63.0)$ & $27(100.0)$ \\
\hline *Significantly higher frequency within group, $p<0.05$ & & & & \\
\hline
\end{tabular}

\section{Informed consent}

The patients were informed of the survey and invited to participate upon their initial visit. Each patient was given written information about the survey along with a letter of consent to be signed and delivered to the provider. The consent was kept with the patient journal. The patient was informed of the right to withdraw from the study at any time without any consequence for the treatment.

\section{Exclusion criteria}

Patients were excluded if they had received external tooth bleaching treatment previously, irrespective of administration and bleaching product. Patients with gingivitis (bleeding on probing) and/or caries in the areas to be bleached were excluded. Pregnant and lactating women were also excluded.

\section{Miscellaneous conditions}

Patients who fulfilled the inclusion criteria were recruited consecutively. The treatment provider decided on either A-H or I-O treatment in concurrence with patient wish and treatment indication. The bleaching procedures were performed according to manufacturers' instructions, but with possible modifications in line with the regular practice of each office. It was required that a dentist diagnosed, supervised and was responsible for the treatment, including choice of products. Other dental personnel such as dental hygienists (bachelor level), dental nurses/ assistants or dental students were allowed to administer the bleaching procedure. The project instructions recommended treatment of a single jaw only.

\section{Methods}

\section{Bleaching procedures}

In $\mathrm{A}-\mathrm{H}$ treatment bleaching trays were custom-made and the resulting designs were described by the providers. The trays were filled with bleaching product and worn as recommended by the treatment provider $(\mathrm{n}=10)$. The $\mathrm{I}-0$ bleaching procedure was performed in the dental office $(n=2)$ by direct application of bleaching gel and optional use of bleaching 
Table 2 Distribution of treatment sites and number of treated teeth among patients in the at-home and in-office groups

\begin{tabular}{|l|l|l|l|l|l|}
\hline Treatment & \multicolumn{2}{l|}{ No. of patients (\%) } & \multicolumn{2}{l}{ Number of treated teeth } \\
\hline & Upper jaw & Lower jaw & Both jaws & Mean \pm SD & Range \\
\hline At-home $(n=143)$ & $116(81.1)$ & $5(3.5)$ & $22(15.4)$ & $11.5 \pm 4.6$ & $6-28$ \\
\hline In-office $(n=28)$ & $16(57.1)$ & $1(3.6)$ & $11(39.3)$ & $14.2 \pm 6.7$ & $8-24$ \\
\hline
\end{tabular}

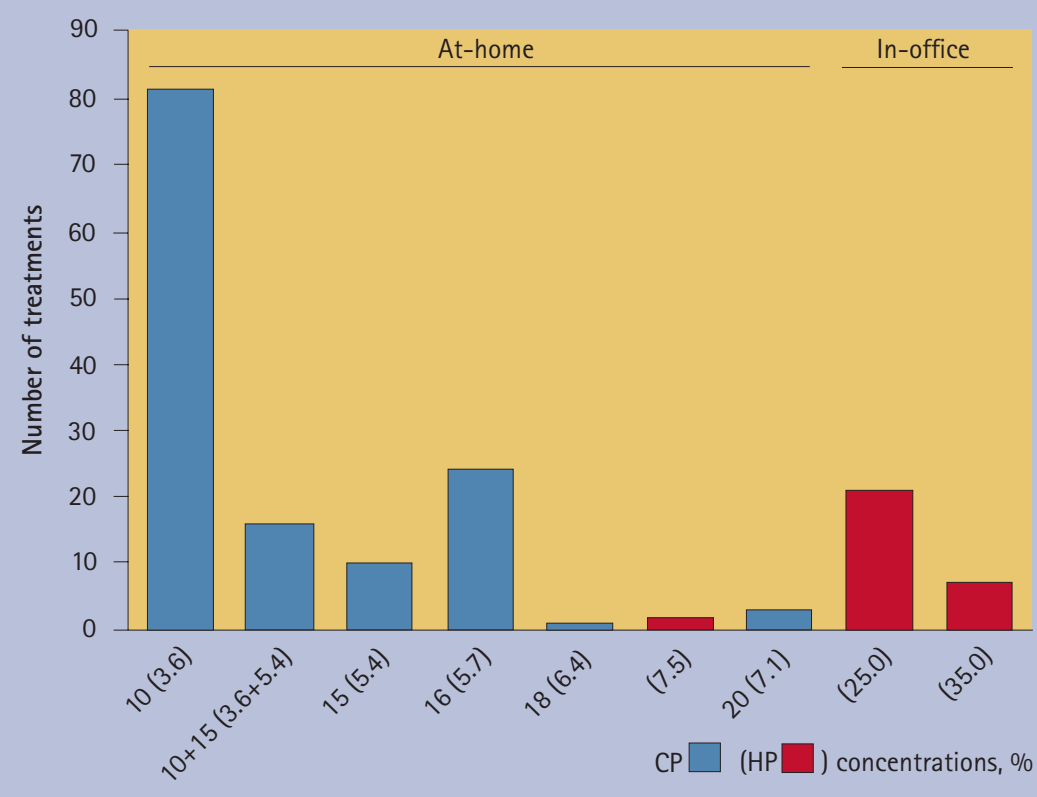

Fig. 2 Group distribution of bleaching agent concentrations. CP: carbamide peroxide; HP: hydrogen peroxide (in parenthesis)

lamp (Fig. 1). All patients were encouraged to report any uncomfortable symptoms so bleaching could be stopped or interrupted.

\section{Survey parts and treatment plan}

An overview of the treatment plan and assessment times is presented in Figure 1. I-O patients were assessed immediately after completion of the bleaching (IPA) in addition to the two follow-up assessments (FUA1 and FUA2). The mean time elapsed from end of treatment to FUA1 was $9.5 \pm 4.4 \mathrm{~d}$ (range: $4-40 \mathrm{~d}$ ) and $14.3 \pm 3.6 \mathrm{~d}$ (range: 6-22 d) for the A-H and I-O groups, respectively. The corresponding mean time to FUA2 was $9.1 \pm 2.8$ months (range: 2-18 months) and $10.0 \pm 2.4$ months (range: 6-13 months), respectively (Fig. 1).

\section{Statistics}

The following descriptive and bivariate statistical tests were used to determine significant differences in side effects between and within groups, and between side effects and study variables: Student's t-test; Mann-Whitney; sign-test;
McNemar; crosstabs with and without quartiles $\left(\chi^{2}\right)$. Regression analysis was used to determine confounders (SPSS/ PASW/IBM SPSS versions 16.0-19.0, IBM Corp, Armork, NY, USA). Means were expressed \pm standard deviations (SD). A p-value less than 0.05 was regarded as statistically significant.

\section{RESULTS}

\section{Study sample}

One hundred and seventy-one persons were enrolled in the survey and 152 (89\%) completed FUA2 (Table 1). Dentists represented $86 \%$ and $100 \%$ of the treatment providers in the A-H and I-O groups, respectively. Other occupations represented in the former group were dental hygienists (1.4\%) and dental assistants/students (12.6\%). An overview of the treatment sites are given in Table 2.

\section{Oral health before treatment}

The most frequently self-reported or observed conditions before treatment are listed in Table 3. 'Gingivitis' (in areas not to be bleached) was included in the list as it was tested as a potential contributing factor to side effects. The conditions tooth brush abrasion, osteogenesis imperfecta, bruxism, acid-induced erosion and exposed/semi-exposed dentin were included in the term 'tooth surface loss'.

\section{Bleaching products and procedures}

The trade names and manufacturers of the bleaching products are listed in Table 4, and the main constituent and concentrations are given in Figure 2. In the A-H group custom-made bleaching trays with reservoir were used for 76.2\% of the patients, and the tray was reported to touch the patient's gingiva in $21 \%$ of the cases. The mean exposure to a bleaching product was 755 (CP-concentration [\%] × time [hours]) (range: 200-2016).

In the I-0 group, light-cured resin barrier was used in all but one treatment, in which a rubber dam was used, to protect gingiva. The 20 patients who underwent light-assisted bleaching were exposed to the same bleaching lamp and used eye protection glasses against irradiation from the lamp (same manufacturer of glasses and lamp). These patients were protected on the lips, tongue and the skin area around the lips by sun tan lotion and/or cotton gauges/textiles, and 25\% of these lightexposed patients had their nose protected as well. The mean exposure to a bleaching product was 22 (HP-concentration [\%] $\times$ time [hours]) (range: 10.5-35.0).

\section{Bleaching treatment duration and interruptions}

The bleaching procedures lasted between 12-154 hours and 30-60 min in the A-H and $\mathrm{I}-\mathrm{O}$ groups, respectively. In both groups, treatment was interrupted by those who experienced side effects (Table 5). Of those who interrupted, $10 \%$ did so more than once. The treatment was resumed in $100 \%$ of the cases in the A-H group. I-O treatment was discontinued and not resumed for two patients (7.1\%).

\section{Side effects - at-home treatment}

Side effects occurred both during the treatment and in the period until FUA1 (Fig. 1, Table 6). The two most frequently occurring effects were tooth sensitivity and 


\begin{tabular}{|c|c|c|c|c|c|c|c|}
\hline \multirow{2}{*}{\multicolumn{2}{|c|}{$\begin{array}{l}\text { Patient } \\
\text { (before treatment) }\end{array}$}} & \multicolumn{3}{|c|}{ At-home $(\mathrm{A}-\mathrm{H})$} & \multicolumn{3}{|c|}{ In-office (I-0) } \\
\hline & & \multirow{2}{*}{$\begin{array}{l}\text { Prevalence } \\
\text { N (\%) } \\
19(13.2)^{\mathrm{a}}\end{array}$} & \multirow{3}{*}{$\begin{array}{l}\text { Tooth sensitivity } \\
\text { All }(n=143) / \\
\text { adjusted }(n=120) \\
\text { ns/ns }\end{array}$} & \multirow{3}{*}{$\begin{array}{l}\text { Gingival irritation } \\
\text { All }(n=143) / \\
\text { adjusted( } n=138) \\
p<0.05^{c} / p<0.05^{c}\end{array}$} & \multirow{2}{*}{\begin{tabular}{|l|}
$\begin{array}{l}\text { Prevalence } \\
\text { N }(\%)\end{array}$ \\
$13(46.4)^{b}$
\end{tabular}} & \multirow{3}{*}{$\begin{array}{l}\text { Tooth sensitivity } \\
\text { All }(n=28) / \\
\text { adjusted }(n=21) \\
\text { ns }\end{array}$} & \multirow{3}{*}{$\begin{array}{l}\text { Gingival irritation* } \\
(\mathrm{n}=28)\end{array}$} \\
\hline Tobacco & Smoking & & & & & & \\
\hline & Snuffing & $16(11.2)^{a}$ & & & $2(7.1)$ & & \\
\hline \multicolumn{2}{|c|}{ Age $<25$ years } & $\mathrm{N} / \mathrm{A}$ & $p<0.05 / p<0.05$ & ns/ns & $\mathrm{N} / \mathrm{A}$ & $n s / n s$ & ns \\
\hline \multicolumn{2}{|l|}{ Gender } & $\mathrm{N} / \mathrm{A}$ & ns/ns & ns/ns & $\mathrm{N} / \mathrm{A}$ & $n s / n s$ & ns \\
\hline \multicolumn{2}{|c|}{ Gingival recession } & 34 (23.8) & ns & ns & $12(42.9)$ & ns & ns \\
\hline \multicolumn{2}{|c|}{ Tooth sensitivity } & $23(16.1)^{a}$ & $p<0.05$ & ns & $7(25.0)$ & ns & ns \\
\hline \multicolumn{2}{|c|}{ Tooth surface loss } & $23(16.1)^{a}$ & $p<0.05$ & ns & $13(46.4)$ & ns & ns \\
\hline \multicolumn{2}{|c|}{ Gingivitis** } & $5(3.5)^{a}$ & ns & $p<0.05$ & $1(3.6)$ & \multicolumn{2}{|c|}{ Too few cases to analyse } \\
\hline \multicolumn{8}{|c|}{ Treatment design } \\
\hline \multicolumn{2}{|c|}{$\begin{array}{l}\text { Bleaching duration } \\
\text { A-H: }>80 \mathrm{~h} ; \mathrm{I}-0: \geq 50 \mathrm{~min}\end{array}$} & $\mathrm{~N} / \mathrm{A}$ & $\mathrm{ns} / \mathrm{ns}$ & $p=0.055 / n s$ & $\mathrm{~N} / \mathrm{A}$ & ns/ns & $p<0.05$ \\
\hline \multicolumn{2}{|c|}{$\begin{array}{l}\text { Concentration of } \\
\text { bleaching product } \\
\text { A-H: }>15 \% \text { CP; } \\
\text { I-O: } 35 \text { vs } 25 \% \text { HP }\end{array}$} & $N / A$ & $\mathrm{~ns} / \mathrm{p}<0.05$ & $p<0.05 / p<0.05$ & N/A & $\mathrm{ns} / \mathrm{p}<0.05$ & $p<0.05$ \\
\hline \multicolumn{2}{|c|}{$\begin{array}{l}\text { Tray contact with gingiva } \\
\text { (A-H) }\end{array}$} & $30(21.0)^{a}$ & $n s / n s$ & $p<0.05 / n s$ & N/A & $N / A$ & $\mathrm{~N} / \mathrm{A}$ \\
\hline \multicolumn{2}{|c|}{$\begin{array}{l}\text { Use of tray reservoir } \\
(\mathrm{A}-\mathrm{H})\end{array}$} & 109 (76.2) & $n s / n s$ & ns/ns & $\mathrm{N} / \mathrm{A}$ & $N / A$ & $\mathrm{~N} / \mathrm{A}$ \\
\hline \multicolumn{2}{|c|}{$\begin{array}{l}\text { Use of bleaching lamp } \\
(I-0)\end{array}$} & N/A & N/A & N/A & $20(71.4)$ & $n s / n s$ & ns \\
\hline
\end{tabular}

gingival irritation/ulceration (abbreviated 'gingival irritation' throughout the text). Eighteen patients (12.6\%) experienced two to three different side effects. Tooth sensitivity and gingival irritation were correlated to patient- and treatment-related variables (Table 3). Tooth sensitivity was reported significantly more often after bleaching than before treatment. The same was true for gingival irritation relative to gingivitis (in areas not to be bleached) ( $p<0.05)$. Excluding tobacco users, suffering from gingivitis before treatment increased the risk of gingival irritation after treatment $(\mathrm{p}<0.05)$. At FUA2, three patients (2.4\%) (Table 1) each reported one of the following side effects: persisting tooth sensitivity, persisting gingival irritation and altered chewing sensation since FUA1. The side effect sub-group at FUA2 was too small for statistical analysis of correlation with predictors. The treatment of two jaws relative to any single jaw did not influence the occurrence of side effects ( $p>0.05$; data not shown).

\section{Side effects - in-office treatment}

Side effects were both reported immediately (IPA) after I-0 bleaching and at FUA1 (Fig. 1; Table 6). Four patients (14.3\%) experienced two to four different side effects at IPA. One patient with four side effects reported tooth sensitivity, gingival irritation, redness/blisters and swelling of the lower lip. Of the 13 patients who reported side effects at IPA, four had persistent symptoms at FUA1 $(\mathrm{p}<0.05)$. The conditions were improved for three and unchanged for one. Eleven new cases of side effects were reported at FUA1 and among those three patients each reported two side effects. Those who reported tooth sensitivity at IPA1 had an increased risk of tooth sensitivity at FUA1 ( $p<0.05)$. Side reactions affected $75 \%$ of the patients within FUA1. Correlation results of patient- and treatment-related predictors for tooth sensitivity and gingival irritation are presented in Table 3. At FUA2 (Table 1), two patients reported onset of side effects; tooth sensitivity and jaw pain, since FUA1. The patient with tooth sensitivity reported this at IPA, but not at FUA1. Tobacco users had higher incidence of side effects ( $p<0.05$ ) than non-tobacco users.

\section{Influence of side effects on patient satisfaction}

Satisfaction with the treatment outcome was unrelated to occurrence of side effects in the A-H group ( $p>0.05$ ) except at FUA2. Patients with side effects were significantly more 'satisfied' or 'very satisfied' with the outcome compared to those without side effects ( $p<0.05$ ). More specifically, there was a significant positive correlation between answering 'very satisfied' and 


\begin{tabular}{l|l|l|}
\hline \multicolumn{3}{|l}{ Table 4 Bleaching products used in the treatments } \\
\hline \multirow{4}{*}{ Treatment } & Bleaching product (trade name) & Manufacturer \\
\hline \multirow{4}{*}{ At-home } & Opalescence & Ultradent Products, Inc., Salt Lake City, UT, USA \\
\cline { 2 - 3 } & Nite White & Discus Dental, Culver City, CA, USA \\
\cline { 2 - 3 } & Day White & Discus Dental \\
\cline { 2 - 3 } & Voco & Bright Smile, Wexford, Ireland \\
\cline { 2 - 3 } & Pola Night & SDI Ltd, Victoria, Australia \\
\cline { 2 - 3 } & Illuminé & Dentsply Ltd., Addlestone, UK \\
\hline \multirow{3}{*}{ In-office } & Opalescence Extra & Ultradent Products, Inc. \\
\cline { 2 - 3 } & ZOOM2 Chairside Whitening Gel & Discus Dental \\
\hline
\end{tabular}

\begin{tabular}{|c|c|c|c|c|c|c|c|}
\hline \multirow{2}{*}{$\begin{array}{l}\text { Prevalence } \\
\text { in group (\%) } \\
(\mathrm{n}=143) \\
14\end{array}$} & \multirow{2}{*}{$\begin{array}{l}\text { Prevalence } \\
\text { in side effect } \\
\text { subgroup (\%) } \\
(\mathrm{n}=84) \\
23.8\end{array}$} & \multicolumn{3}{|c|}{ Days until onset of interruption } & \multicolumn{3}{|c|}{ Duration (days) of interruption } \\
\hline & & Mean & SD & Range & Mean & SD & Range \\
\hline & & 3.6 & 2.2 & $1-10$ & 2.3 & 1.7 & $1-8$ \\
\hline
\end{tabular}

reporting tooth sensitivity ( $\mathrm{p}<0.05)$. In the I-0 group no correlation was found between any level of satisfaction with treatment outcome and the occurrence of any single or pooled side effects at IPA, FUA1 and FUA2 ( $p>0.05)$.

\section{Side effects at-home versus in-office}

The number of gingival irritation cases was significantly higher after I-O than A-H treatment at FUA1 ( $p<0.05)$. This effect was statistically influenced by the number of tobacco users $(\mathrm{p}<0.05)$. The risk for developing either tooth sensitivity alone or combined tooth sensitivity/gingival irritation was similar for the two groups within FUA1 ( $p>0.05)$.

\section{Supplementary dental treatment}

The treatment provider recommended replacement of fillings for $6.3 \%(n=143)$ and 25\% $(\mathrm{n}=28)$ in the A-H and I-O groups, respectively, upon completion of bleaching treatment ( $p<0.05$ in the respective groups).

\section{DISCUSSION}

\section{Material and methodology}

Statistical comparison of the treatment groups may have been influenced by different group sizes, observation times, number of treatment providers and patient-related factors before treatment (Table 3). To limit
Fig. 1) was performed later than in other studies with shorter observation times. ${ }^{3,15}$ Most of the tooth sensitivity days occurred during the early part of A-H treatment. ${ }^{16}$ However, tooth sensitivity expressed as sensitivity to hot or cold tended to occur later during a 14-day bleaching cycle. ${ }^{17}$ Comparison of the number of tooth sensitivity cases between studies is difficult as this side effect is interchangeably reported as prevalence, incidence or number of people affected. Sensitivity varied from 0 to $100 \%$ affected ${ }^{12}$ depending on bleaching method, ${ }^{18}$ and the symptoms varied from mild to severe. Incidences of tooth sensitivity were 15-65\% after A-H bleaching and 55-78\% after I-O bleaching in combination with heat. ${ }^{7,14,19-21}$ Prevalence of tooth sensitivity was 15\% the day after I-O and 35\% five days after A-H treatment (study partially supported by Vita Zahnfabrik). ${ }^{6}$ The same trend was found in the current study, however; when post-treatment times were equal there was no significant difference in the sensitivity prevalence between $\mathrm{A}-\mathrm{H}$ and I-0. Possible use of desensitising products was not recorded. However, according to some manufacturers' written information the I-O procedure included additional use of a fluoride and potassium nitrate gel, claimed to minimise sensitivity. Whether the A-H treatment included desensitising compounds and whether or not these were used is unknown. If desensitising compounds were used to a greater extent in conjunction with I-O, it may have contributed to the lower prevalence of tooth sensitivity at IPA (Table 6).

\section{Treatment-induced gingival irritation}

Reported prevalence of gingival irritation after A-H treatment was 0-62\% depending on application type: strip, gel in tray, paint-on gel or film. ${ }^{12}$ In comparison, the prevalence of $14 \%$ at FUA1 after A-H treatment in the present study was in the lower range (Table 6). However, the prevalence of 36\% within FUA1 after I-0 treatment was close to those reported after A-H treatment: $31 \%{ }^{22}$ and 34\%. ${ }^{17}$ Additionally, the prevalence of around 15\% gingival irritation observed at FUA1 after A-H treatment was similar to that of the study from Marson et al. ${ }^{19}$ of I-O treatment. Most investigations were based on subjective answers. However, Kirsten 
Table 6 Number and prevalence (\%) of side effects reported at first follow-up (FUA1) after at-home treatment and at immediate post-treatment assessment (IPA) and FUA1 after in-office treatment

\begin{tabular}{|c|c|c|c|c|c|}
\hline \multirow{3}{*}{ Type of adverse effect } & \multirow{3}{*}{$\begin{array}{l}\text { At-home } \\
(\mathrm{n}=143) \text { No. of } \\
\text { cases in treatment } \\
\text { group }(\%) \\
\text { FUA1 }\end{array}$} & \multicolumn{4}{|c|}{ In-office $(n=28)$ No. of cases in treatment group $(\%)$} \\
\hline & & \multirow{2}{*}{ IPA } & \multicolumn{2}{|l|}{ FUA1 } & \multirow{2}{*}{ Total within FUA1 } \\
\hline & & & All & New cases since IPA & \\
\hline Total & $104(72.7)$ & $19(67.9)$ & $18(64.3)$ & $11(39.3)$ & $30(107.0)$ \\
\hline $\begin{array}{l}\text { Total adjusted } \\
\text { At-home }(n=97)\end{array}$ & $87(60.8)$ & - & - & - & - \\
\hline Tooth sensitivity & $72(50.3)$ & $7(25.0)$ & $9(32.1)$ & $4(14.3)$ & $11(39.3)$ \\
\hline Dry mouth & $1(0.7)$ & 0 & 0 & 0 & 0 \\
\hline Gingival irritation/ulceration & $20(14.0)$ & $7(25.0)$ & $4(14.3)$ & $3(10.7)$ & $10(35.7)$ \\
\hline Sore throat & $1(0.7)$ & 0 & 0 & 0 & 0 \\
\hline Toothache $^{* *}$ & $2(1.4)$ & $1(3.6)$ & $4(14.3)$ & $3(10.7)$ & $4(14.3)$ \\
\hline Jaw/jaw joint pain & $1(0.7)$ & 0 & 0 & 0 & 0 \\
\hline Redness/blisters on tongue/lips/in the face & 0 & $2(7.1)$ & $1(3.6)$ & $1(3.6)$ & $3(10.7)$ \\
\hline Swelling of lips/tongue & $1(0.7)$ & $1(3.6)$ & 0 & 0 & $1(3.6)$ \\
\hline Eye pain/sight disturbances & N/A & 0 & 0 & 0 & 0 \\
\hline Other & $6(4.2)$ & $1(3.6)$ & 0 & 0 & $1(3.6)$ \\
\hline
\end{tabular}

et $a l .{ }^{23}$ detected inflammation cells, and found that immediately after A-H treatment with 16\% CP in trays with reservoirs, 100\% of the patients experienced inflammation in the gingiva. Thirty days later the prevalence was reduced to $16 \%$. Thus, the timing of investigation should be reported. The significantly higher prevalence of gingival irritation/ulceration in the I-O group compared with the A-H group of the current study may be explained by leakage of bleaching product below the gingival barrier due to improper isolation of the gingival tissue.

\section{Combination side effects}

At least one side effect was experienced by $50 \%$ and $60 \%$ in the A-H and I-O groups respectively (data not shown). The prevalence of combined tooth sensitivity and gingival irritation in the I- 0 group was influenced by tobacco use ( $p<0.05$; data not shown). Several studies combined tooth sensitivity and gingival irritation when reporting side effects. Prevalence of combined effects in A-H treatments varied between 51-66\%. ${ }^{12,22,24}$ 'Sensitivity' has been used to describe sensitivity to hot or cold, gingival irritation or irritation of tongue and throat. ${ }^{17}$ The prevalence of multiple side effects in an A-H study was $47 \%(n=172) .{ }^{17}$ A few studies reported no side effects. ${ }^{12}$

\section{Persistence of symptoms and/or late development}

Despite the relatively small I-0 group size, a trend of higher prevalence of side effects was seen compared to A-H at FUA2 up to 13 months. Persistence of symptoms was reported in the range 0-73\% and durations of 24 h-45 days depending on type of treatment. ${ }^{6,15-17,23-26}$ The present survey was not designed to answer whether the side effects were felt continuously or intermittently between FUA1 and FUA2 or whether or not the symptoms originated from sources other than the bleaching treatment. It is difficult to relate longterm effects to a previous treatment due to the possible influence of other factors. Placebo controls are seldom used (see for example ${ }^{24}$ ). However, no difference in side effects was found when exposure to a bleaching product and a placebo control 2 weeks after treatment were compared. ${ }^{12}$ No studies investigating side effects between 45 days and 9-10 months were found in the literature.

\section{Predictors of side effects}

\section{Pre-existing conditions}

Different group sizes may have contributed to the relative influence of predictors on side effects (Table 3). Despite higher prevalence of both pre-existing conditions and side effects in the I-O group, significant correlations were absent (Tables 3 and 6). Contrary to Leonard et al., ${ }^{24}$ we found that young age and tooth surface loss were predictors for tooth sensitivity in A-H treatments. The current study confirmed pre-existing sensitivity as a predictor for bleachinginduced tooth sensitivity. ${ }^{24}$ However, gingival recession was not correlated with any side effects (Table 3) in contrast to the findings by Jorgensen et al. ${ }^{27}$ The study questionnaire did not include gingival irritation as a patient specific variable before bleaching (Table 3). However, since preexisting gingivitis was positively correlated with gingival irritation in the $\mathrm{A}-\mathrm{H}$ group, further correlations with gingival irritation were adjusted for gingivitis (Table 3). No reports have addressed gingivitis or tooth surface loss for example, as predictors for gingival irritation. Pre-existing gingivitis significantly increased the frequency of 
gingival irritation among non-smokers ( $p<0.05$; data not shown).

\section{Tobacco use}

The number of tobacco users was highest in the I-0 group (Table 3), and it consisted mainly of daily cigarette smokers (67\% of tobacco users) (data not shown). Sixtyone percent of the tobacco users in this group experienced side effects versus 33\% of the non-tobacco users (data not shown). In contrast, in the A-H group there was a weak negative correlation between tobacco use and gingival irritation (Table 3). This finding was supported by a small A-H study $(\mathrm{n}=18)$ in which no increase in gingival irritation among smokers was found. ${ }^{28}$ It may be hypothesised that the tobacco users were protected from development of gingival irritation by upregulation of antioxidants such as glutathione (GSH) following initial HP-induced GSH depletion ${ }^{29}$ or by immune suppression. Furthermore, tobacco users in the A-H group may have refrained from such use while bleaching until FUA1, whereas the tobacco users in the I-0 group may have resumed their habit closely after treatment. Whether these opposite influences were due to a different pattern of tobacco use or to the sizes of the tobacco sub-groups, is not known. It was unexpected that tobacco use had contradictory influence on side effects on the two treatment groups.

\section{Effect of concentration}

The concentration difference of the two products used in the I- 0 treatment might have been even smaller than ten percentage points (Fig. 2). According to the manufacturer's safety data sheet the concentration of the product labelled $25 \%$ HP contained 25-30\%. It cannot be ruled out that the significant correlation between side effects and the highest concentration could be ascribed to other factors influencing the treatment in the two clinics where I-0 bleaching was performed. The constituents, ${ }^{3}$ rather than the concentrations, may have contributed to the onset of side effects. The highest concentration induced higher incidence of tooth sensitivity in a study comparing 10 and $16 \% \mathrm{CP}$ in A-H treatment $(\mathrm{n}=92) .{ }^{30}$ Also, tooth sensitivity dependence on $\mathrm{CP}$ concentration was reported in $\mathrm{A}-\mathrm{H}$ treatment, admittedly without information on statistical significance. ${ }^{31}$ However, these findings were not supported by CP studies of smaller sizes ${ }^{12,14}$ than that of Meireles et $a l .{ }^{30}$ The significant correlation between a CP concentration above $15 \%$ and gingival irritation in the A-H group supported the finding ${ }^{14}$ that $16 \%$ CP caused more irritation than 10\% $\mathrm{CP}$. The observation that the amount of HP recovered in the pulp was influenced by the concentration of the bleaching agent ${ }^{32,33}$ could explain the dose-related frequency of side effects. In contrast, no difference in prevalence of tooth sensitivity or gingival irritation was found after comparison of bleaching methods with HP concentrations $3.3-38 \%{ }^{1}$ in strips and trays.

\section{Effect of time and total exposure}

I-O treatment was performed continuously with a constant bleaching gel concentration whereas A-H treatment was performed intermittently and sometimes with varying concentrations. The latter treatment constituted a larger range of treatment duration. Despite this larger range the exposure levels (concentration $\times$ time) influenced the number of side effects similarly, both single and combined effects ( $p>0.05$; data not shown). Thus, the total bleaching exposure was not a critical factor for development of side effects in this study. The number of daily bleaching applications is considered a predictor for sensitivity. ${ }^{3}$ Also, enamel changes and the amount of HP found in pulp have been positively correlated with exposure time and concentration of HP. ${ }^{10}$

\section{Effect of tray contact with gingiva}

Tray design, fit, and faulty application are predictors for gingival irritation. ${ }^{3,34}$ Tray contact with gingiva was a predictor in the present study (Table 3). However, the finding that gingival contact with tray was reported in as much as $20 \%$ of the A-H group was unexpected. Poor fit resulting in tray contact was independent of dental occupation, ie one dentist reported two-thirds of the cases. Contrary to the findings by Kirsten et $a .^{23}$ the use of reservoirs, irrespective of bleaching agent concentration (Fig. 2), did not influence side effects in the current study (Table 3).
Effect of light-assisted bleaching

The frequencies of side effects following either light-assisted or conventional I-0 bleaching of similar exposure times were $70 \%$ and $63 \%(\mathrm{n}=28)$, respectively, ( $p>0,05$; data not shown). Theoretically, the gingiva, tongue, lips, eyes ${ }^{35}$ and pulp $^{34}$ may be affected by irradiation, including heat, from bleaching lamps, but in the present study fluid rubber dam and other physical barriers as well as lightprotective glasses were used. Another study confirmed the lack of sensitivity after light-assisted bleaching, ${ }^{19}$ while increased tooth sensitivity was reported after bleaching with HP and light relative to HP only. ${ }^{18,36}$ Three of the patients who underwent light-assisted treatment used potentially photosensitising medication. However, it is difficult to ascribe the use of such drugs to tooth sensitivity and gingival irritation. Detection of photosensitising reactions was unlikely due to the small group size and difficulty in diagnosis. ${ }^{37}$

\section{Discontinuation of treatment due to sensitivity}

The prevalence of interruptions in this study confirmed previous findings: $14 \% 0^{25}$ and $20 \%{ }^{24}$ discontinued A-H treatment with 10\% CP due to discomfort/tooth sensitivity. In contrast, no participants ( $\mathrm{n}=172$ ) withdrew due to sensitivity from an Ultradent-supported study with $10 \%$ CP bleaching agents. ${ }^{17}$ The authors suggested that this result could be ascribed to the additives potassium nitrate and sodium fluoride in the gel. The reason for resuming treatment in the $\mathrm{A}-\mathrm{H}$ group (Table 5) may have been that symptoms were transient and weaker than those in the I-O group. Percentage treatment interruptions/discontinuation could serve as a semi-objective measure of severity of side effects.

\section{Influence of side effects on patient satisfaction}

The experience of side effects in the A-H group did not lessen the satisfaction with the bleaching treatment. Indeed, at FUA2 the likelihood of being very satisfied with the treatment increased with the experience of tooth sensitivity. This unpredictable result was contrary to the suggestion ${ }^{17}$ that tooth sensitivity had a negative influence on patient satisfaction. 


\section{CONCLUSION}

Bleaching treatment, irrespective of method, caused a high prevalence of side effects even when initiated, performed and closely monitored by dental personnel. Although most side effects were reversible, a small percentage of the patients were still suffering up to a year after treatment. Tooth sensitivity, tooth surface loss and young age at inclusion, as well as concentration of bleaching product and tray contact with gingiva, increased the risk of side effects. Patients should be treated only if bleaching is indicated based on a proper diagnosis.

The authors would like to thank the participating dentists and patients for their contribution to this survey. We acknowledge the valuable statistical expertise of Professor Leiv Sandvik, Faculty of Odontology, University of Oslo and the help with the data entry provided by Ms Liv Christiansen and Ms Anne Wesmann, NIOM. This study was funded by the Norwegian Directorate of Health (Project No. 05/6,350).

1. Auschill T M, Hellwig $E_{1}$ Schmidale $S$, Sculean $A_{1}$ Arweiler N B. Efficacy, side-effects and patients' acceptance of different bleaching techniques (OTC in-office, at-home). Oper Dent 2005; 30: 156-163.

2. Christensen $\mathrm{GJ}$ J. Are snow-white teeth really so desirable? J Am Dent Assoc 2005; 136: 933-935.

3. Burrows $S$. A review of the safety of tooth bleaching. Dent Update 2009; 36: 604-614.

4. Thickett E, Cobourne M T. New developments in tooth whitening. The current status of external bleaching in orthodontics. J Orthod 2009; 36: 194-201.

5. Thosre D, Mulay S. Smile enhancement the conservative way: Tooth whitening procedures. J Conserv Dent 2009: 12: 164-168.

6. da Costa J B, McPharlin R, Paravina R D, Ferracane $J$ L. Comparison of at-home and in-office tooth whitening using a novel shade guide. Oper Dent 2010; 35: 381-388.

7. Dahl J E, Pallesen U. Tooth bleaching-a critical review of the biological aspects. Crit Rev Oral Biol Med 2003; 14: 292-304.

8. Goldberg M, Grootveld M, Lynch E. Undesirable and adverse effects of tooth-whitening products: a review. Clin Oral Investig 2010; 14: 1-10.

9. Tredwin C J, Naik S, Lewis N J, Scully C. Hydrogen peroxide tooth-whitening (bleaching) products: review of adverse effects and safety issues. Br Dent J 2006; 200: 371-376.

10. Minoux M, Serfaty R. Vital tooth bleaching: biologic adverse effects-a review. Quintessence Int 2008; 39: 645-659.

11. Act on personal health data filing systems and the processing of personal health data of 18-05-2001 (with amendments made previous to 1-11-2002), Personal Health Data Filing System Act/24. Oslo: Ministry of Health and Care Services, 2001.

12. Hasson H, Ismail A I, Neiva G. Home-based chemically-induced whitening of teeth in adults (Review). Cochrane Database Syst Rev 2006; 4: CD006202.

13. Leonard RH Jr. Efficacy, longevity, side effects, and patient perceptions of nightguard vital bleaching. Compend Contin Educ Dent 1998; 19: 766-781.

14. Leonard R H Jr, Garland G E, Eagle J C, Caplan D J. Safety issues when using a $16 \%$ carbamide peroxide whitening solution. J Esthet Restor Dent 2002; 14: 358-367.

15. Cohen $S$ C, Chase $C$. Human pulpal response to bleaching procedures on vital teeth. J Endod 1979; 5: 134-138.

16. Tam L. Clinical trial of three $10 \%$ carbamide peroxide bleaching products. J Can Dent Assoc 1999; 65: 201-205.

17. Browning W D, Blalock J S, Frazier K B, Downey M C, Myers M L. Duration and timing of sensitivity related to bleaching. J Esthet Restor Dent 2007; 19: 256-264.

18. Amengual J, Forner L. Dentine hypersensitivity in dental bleaching: case report. Minerva Stomatol 2009; 58: 181-185.

19. Marson FC, Sensi L G, Vieira L C, Araújo E. Clinical evaluation of in-office dental bleaching treatments with and without the use of light-activation sources. Oper Dent 2008; 33: 15-22.

20. Li Y. Safety controversies in tooth bleaching. Dent Clin North Am 2011; 55: 255-263.

21. Nathanson D. Vital tooth bleaching: sensitivity and pulpal considerations. J Am Dent Assoc 1997; 128 Suppl: 41S-44S.

22. Haywood V B, Leonard R H, Nelson C F, Brunson W D. Effectiveness, side effects and long-term status of nightguard vital bleaching. J Am Dent Assoc 1994; 125: 1219-1226.

23. Kirsten $G A$, Freire $A$, de Lima $A$ A, Ignácio $S A$, Souza $E$ M. Effect of reservoirs on gingival inflammation after home dental bleaching. Quintessence Int 2009; 40: 195-202.
24. Leonard R H Jr, Haywood V B, Phillips C. Risk factors for developing tooth sensitivity and gingival irritation associated with nightguard vital bleaching. Quintessence Int 1997; 28: 527-534.

25. Schulte JR, Morrissette D B, Gasior E J, Czajewski $M V$. The effects of bleaching application time on the dental pulp. J Am Dent Assoc 1994; 125: 1330-1335.

26. Reis A, Tay L Y, Herrera D R, Kossatz S, Loguercio A D. Clinical effects of prolonged application time of an in-office bleaching gel. Oper Dent 2011; 36: 590-596.

27. Jorgensen $M$ G, Carroll W B. Incidence of tooth sensitivity after home whitening treatment. J Am Dent Assoc 2002; 133: 1076-1082.

28. Almas K, Al-Harbi M, Al-Gunaim M. The effect of a 10\% carbamide peroxide home bleaching system on the gingival health. J Contemp Dent Pract 2003; 4: 32-41.

29. Volk J, Leyhausen G, Dogan S, Geurtsen W. Additive effects of TEGDMA and hydrogenperoxide on the cellular glutathione content of human gingival fibroblasts. Dent Mater 2007; 23: 921-926.

30. Meireles S S, Heckmann S S, Leida F L, dos Santos Ida S, Della Bona A, Demarco F F. Efficacy and safety of $10 \%$ and $16 \%$ carbamide peroxide tooth-whitening gels: a randomized clinical trial. Oper Dent 2008; 33: 606-612.

31. Gerlach R W, Gibb R D, Sagel P A. A randomized clinical trial comparing a novel $5.3 \%$ hydrogen peroxide whitening strip to $10 \%, 15 \%$, and $20 \%$ carbamide peroxide tray-based bleaching systems. Compend Contin Educ Dent Supp/ 2000; 29: S22-S28.

32. Benetti A R, Valera M C, Mancini M N, Miranda C B, Balducci I. In vitro penetration of bleaching agents into the pulp chamber. Int Endod J 2004; 37: 120-124.

33. Gökay 0 , Müjdeci A, Algn E. Peroxide penetration into the pulp from whitening strips. J Endod 2004; 30: $887-889$

34. Tooth bleaching treatments. A review. Paris: Association Dentaire Française, 2007.

35. Bruzell E M, Johnsen B, Aalerud T N, Dahl J E, Christensen $\mathrm{T}$. In vitro efficacy and risk for adverse effects of light-assisted tooth bleaching. Photochem Photobiol Sci 2009; 8: 377-385

36. Kugel G, Ferreira S, Sharma S, Barker M L, Gerlach R W. Clinical trial assessing light enhancement of in-office tooth whitening. J Esthet Restor Dent 2009; 21: 336-347.

37. Ferguson J. Photosensitivity due to drugs. Photodermatol Photoimmunol Photomed 2002; 18: 262-269. 